\title{
Review \\ Exposure and Health Effects of Bacteria in Healthcare Units: An Overview
}

\author{
Ana Monteiro ${ }^{1,2,3, *(\mathbb{D})}$, Jéssica Cardoso ${ }^{4}$, Nuno Guerra ${ }^{4}$, Edna Ribeiro ${ }^{1}\left(\mathbb{C}\right.$, Carla Viegas ${ }^{1,5}{ }^{(\mathbb{C}}$, \\ Sandra Cabo Verde ${ }^{3}$ and António Sousa-Uva ${ }^{2,5}$
}

Citation: Monteiro, A.; Cardoso, J.; Guerra, N.; Ribeiro, E.; Viegas, C.; Cabo Verde, S.; Sousa-Uva, A. Exposure and Health Effects of Bacteria in Healthcare Units: An Overview. Appl. Sci. 2022, 12, 1958. https://doi.org/10.3390/ app12041958

Academic Editor: Elza Bontempi

Received: 11 January 2022

Accepted: 10 February 2022

Published: 13 February 2022

Publisher's Note: MDPI stays neutral with regard to jurisdictional claims in published maps and institutional affiliations.

Copyright: (C) 2022 by the authors. Licensee MDPI, Basel, Switzerland. This article is an open access article distributed under the terms and conditions of the Creative Commons Attribution (CC BY) license (https:// creativecommons.org/licenses/by/ $4.0 /)$.
1 H\&TRC - Health \& Technology Research Center, ESTeSL_Escola Superior de Tecnologia da Saúde, Instituto Politécnico de Lisboa, 1600-560 Lisbon, Portugal; edna.ribeiro@estesl.ipl.pt (E.R.); carla.viegas@estesl.ipl.pt (C.V.)

2 Escola Nacional de Saúde Pública, Universidade NOVA de Lisboa, 1600-560 Lisbon, Portugal; asuva@ensp.unl.pt

3 Centro de Ciências e Tecnologias Nucleares (C2TN), Instituto Superior Técnico, Universidade de Lisboa, 1600-560 Lisbon, Portugal; sandracv@ctn.tecnico.ulisboa.pt

4 Escola Superior de Tecnologia da Saúde de Lisboa, Instituto Politécnico de Lisboa, 1600-560 Lisbon, Portugal; jesscrds@hotmail.com (J.C.); nunomguerra@gmail.com (N.G.)

5 Centro de Investigação em Saúde Pública, Universidade NOVA de Lisboa, 1600-560 Lisbon, Portugal

* Correspondence: ana.monteiro@estesl.ipl.pt

\begin{abstract}
Healthcare units consist of numerous people circulating daily, such as workers, patients, and companions, and these people are vehicles for the transmission of microorganisms, such as bacteria. Bacteria species may have different allergenic, pathogenic, infectious, or toxic properties that can affect humans. Hospital settings foment the proliferation of bacteria due to characteristics present in the indoor hospital environment. This review article aims to identify the potential health effects caused by bacterial contamination in the context of healthcare units, both in patients and in workers. A search was carried out for articles published in PubMed, Web of Science and Scopus, between 1 January 2000 and 31 October 2021, using the descriptor hospital exposure assessment bacteria. This bibliographic research found a total of 13 articles. Bacteria transmission occurs mainly due to the contact between healthcare workers and patients or through the handling of/contact with contaminated instruments or surfaces. The most common bacterial contaminants are Escherichia coli, Pseudomonas aeruginosa, Staphylococcus spp., Staphylococcus aureus and Micrococcus luteus, and the principal health effects of these contaminants are hospital-acquired infections and infections in immunocompromised people. A tight control of the disinfection methods is thus required, and its frequency must be increased to remove the microbial contamination of wards, surfaces and equipment. A better understanding of seasonal variations is important to prevent peaks of contamination.
\end{abstract}

Keywords: exposure; health effects; healthcare-associated infections; bacterial contamination; healthcare units; hospital

\section{Introduction}

Infections associated with healthcare units are a major public health problem that concerns patients, the public, and politicians, since they impact society's development [1] These infections lead to significant mortality and financial losses for health systems each year. Therefore, the rate of infection associated with healthcare units is not only an indicator of patient safety but also of the global healthcare quality provided in hospitals [2-4]. According to the World Health Organization (WHO), for every 100 hospitalized patients at any given time, 7 in developed countries and 10 in developing countries will acquire at least one healthcare-associated infection [2]. Another survey indicated that 1 in 17 hospitalized patients who received healthcare-associated infections (while being treated for other health issues) died as a result [5]. 
Healthcare units such as hospitals, maternity centers, blood banks, clinics, medical offices, urgent care centers, or healthcare centers consist of countless people circulating daily, such as workers, patients and their companions, the healthy and the sick. These people are vehicles for transmitting microorganisms, such as bacteria, that can cause infections that are transmitted very easily in this setting due to its population of sick or immunocompromised people [6].

Additionally, bacterial contamination in hospitals is heavily affected by the following important factors: construction characteristics, levels of water and nutrients in the interior environment necessary for the growth and survival of bacteria, people that occupy the space, and the outdoor environment [7]. Medical activities, cleaning procedures and their frequency are crucial factors for the increase in bacterial load $[8,9]$.

Bacterial species have different allergenic, pathogenic, infectious, or toxic properties that can affect humans [10]. Allergenic bacteria, mainly thermophilic bacteria, may generate a hypersensitivity response (hypersensitivity pneumonitis) in the host [10]. A pathogenic bacterium causes disease in a host and is determined by virulence factors, enabling the replication and dissemination of bacteria in the host organism [11,12]. Bacteria infect a host, usually from another host/reservoir, through direct contact, airborne transmission, a vector, or a common vehicle [10]. In addition, bacteria can produce toxins, which trigger a harmful process in the host organism, inhibiting protein synthesis, activating immune responses, and damaging cell membranes [13]. Bacterial cell wall constituents, such as endotoxins and peptidoglycans, are referred to as agents with pro-inflammatory properties causative of respiratory symptoms (asthma, bronchitis and byssinosis) [10].

The transmission of bacteria can be promoted because healthcare workers interact physically with different patients, unaware that they are transmitting potentially pathogenic agents. Additionally, the handling/contact with contaminated instruments or surfaces $[14,15]$ can cause a risk of infection in both workers [16] and patients. In fact, the isolation of microorganisms from the surfaces suggests that some patients acquire bacterial infections in the hospital [17-20].

Hospital-acquired (nosocomial) infections are a concern in terms of patient safety, as they may have a high impact on patient morbidity and mortality [21,22].

Commonly, most bacteria do not cause adverse health effects and can even benefit us and the environment. The problem arises when the concentration of certain potentially pathogenic bacteria is higher than the infective dose, which varies dramatically across pathogen species [23]. The scale of the severity of the effects on human health depends on many factors such as toxicity, exposure time and microbial load, and even one's age and nutritional status [24]. For example, bacteria such as Acinetobacter baumannii, Pseudomonas aeruginosa and Stenotrophomonas maltophiliam, which are non-fermenting Gram-negative bacilli, can cause infections and severe health problems. These bacteria have been recognized as multidrug-resistant (MDR) and are associated with higher rates of mortality, increased service costs, and a poorer clinical outcome [25-28]. Additionally, Burkholderia cepacia complex $(\mathrm{Bcc})$, which are a non-fermenting Gram-negative bacillus, consist of 20 species that are similar in phenotype and genetically different [29]. During the last two decades, Bcc were considered the most common bacteria in intensive care units, and recognized as a nosocomial pathogen, associated with several outbreaks in immunocompromised patients [28], such as bloodstream infections, pneumonia, urinary tract infections, septic arthritis, and peritonitis [30,31].

For the healthcare sector, the priority is to reduce, prevent and monitor infections to provide a high-quality service with the fewest number of health conditions. Therefore, healthcare units must adopt strategies and systems of epidemiologic surveillance to control infections.

In order to improve public health, this article intends to describe prevalent bacteria and identify their potential health effects in the context of healthcare units, both in patients and in workers. For these, it is important to assess the factors that influence bacterial contamination in this setting. This will ultimately contribute to the prioritization of actions 
to establish procedures for evaluating occupational exposure, protocols, and guidelines adaptable to healthcare units, which have an increased risk of the transmission of infections due to prolonged exposure periods and the high density of people.

\section{Materials and Methods}

\subsection{Systematic Review Registration}

The protocol of this systematic review was submitted for registration in PROSPERO (https:/ / www.crd.york.ac.uk/prospero/, accessed on 18 December 2021 ) (Registration Number: 291564). Moreover, the Preferred Reporting Items for Systematic Reviews (PRISMA) checklist was completed (Table S1—Supplementary Material).

\subsection{Search Strategy and Inclusion and Exclusion Criteria}

In this study, available data on the exposure assessment of bacteria, including hospitals and healthcare units, published between 1 January 2000 and 31 October 2021, were searched following the Preferred Reporting Items for Systematic Reviews and Meta-Analysis methodology. The databases chosen were PubMed, Web of Science, and Scopus. Searches were carried out in English. The search terms were "Exposure assessment bacteria" and "Hospital" and "Health Care Units". Articles that did not meet the inclusion criteria and duplicates were excluded from further analysis (Table 1).

Table 1. Inclusion and exclusion criteria in the articles selected.

\begin{tabular}{cc}
\hline Inclusion Criteria & Exclusion Criteria \\
\hline $\begin{array}{c}\text { Articles in the English language } \\
\text { Articles published from 1 January 2000 to } \\
\text { 31 October 2021 }\end{array}$ & $\begin{array}{c}\text { Articles in other languages (for articles) } \\
\text { Articles published before 2000 } \\
\text { healthcare units }\end{array}$ \\
$\begin{array}{c}\text { Articles related to bacteria contamination in related to health effects of bacteria } \\
\text { on humans }\end{array}$ & $\begin{array}{c}\text { Articles related to biological samples from } \\
\text { patients or workers(exclusive) } \\
\text { Abstract of congress, reviews/state-of-the } \\
\text { art, reports }\end{array}$ \\
$\begin{array}{c}\text { Articles related exclusively to humans } \\
\text { Bacterial identification to the genera level and } \\
\text { if possible, to the species level. }\end{array}$ & Articles related exclusively to animals \\
\hline
\end{tabular}

\subsection{Studies Selection and Data Extraction}

Initially, all titles and abstracts were selected, and then only the full texts of all potentially relevant studies were reviewed, considering the inclusion and exclusion criteria. The following information was manually selected: (1) title, (2) analyzed country, (3) analyzed environment, (4) collected data, (5) results, (6) bacteria found, (7) health effects and (8) affected population.

\subsection{Quality Assessment}

In each study, we assessed the bacterial results, type of bacteria found, and health effects in order to eliminate the risk of bias and ensure that each study was complying with the inclusion criteria focused on bacterial contamination, health effects and the fact that the study was performed in a clinical environment.

\section{Results}

Figure 1 illustrates the process used to identify and select the articles for analysis. The primary search on the databases returned 1049 studies from which 1003 abstracts were screened, and 125 full texts were assessed for eligibility. After considering the inclusion and exclusion criteria, we were able to select 44 articles. This review is centered on 13 articles about the context of exposure assessment bacteria in hospital and healthcare units. 


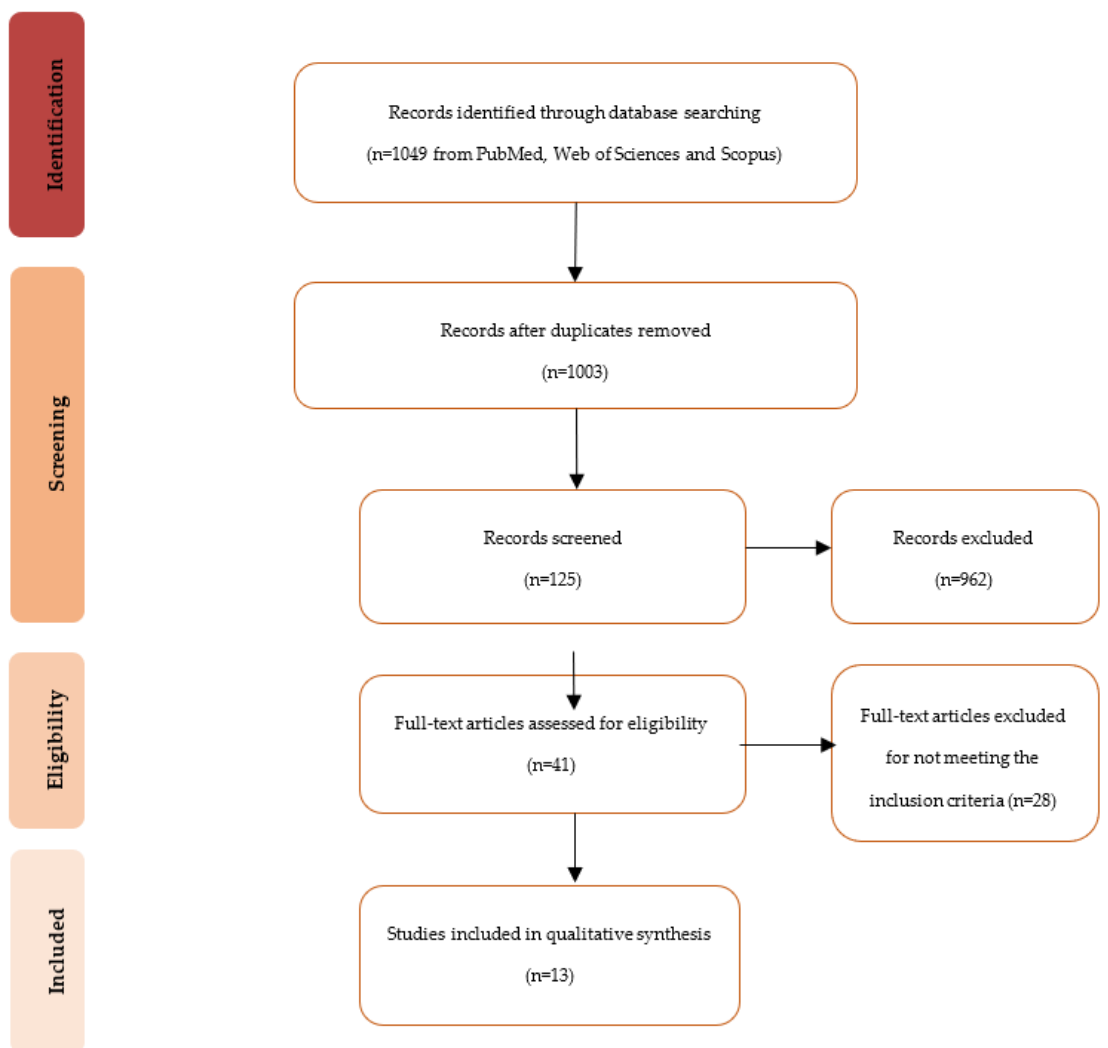

Figure 1. PRISMA-based selection of articles.

\subsection{Characteristics of the Selected Studies}

The selected articles (13) were studied in terms of reference values of bacteria and health effects that could be caused by bacteria. The obtained data can be found in Table 2 . These studies were conducted in several countries such as Italy, Poland, The United States of America, Korea, Pakistan, Greece, Uganda, Iran, Brazil, and Tehran. For the assessment of bacteria, more than half of the studies used air samples (7 out of 13), others used settle plates and swab methods, and some did not disclose the method used to assess bacteria.

\subsubsection{Reference Values for Bacteria}

Regarding the reference values for bacteria, the median level of colony forming units (CFU) in the wards of hospital 1 was 129.87 (87.46-268.97) CFU $/ \mathrm{m}^{3}$ and, for hospital 2, was 297.97 (217.66-431.85) CFU $/ \mathrm{m}^{3}$ [32], both part of a teaching hospital in Tehran. A study conducted in a Brazilian hospital reported median bacterial loads of $345.25 \mathrm{CFU} / \mathrm{m}^{3}$ in the postsurgical restroom and $566 \mathrm{CFU} / \mathrm{m}^{3}$ in operating theatres [33]. Another study in a hospital from Poland reported a median bacterial load of $347.4 \mathrm{CFU} / \mathrm{m}^{3}\left(257.1-436.3 \mathrm{CFU} / \mathrm{m}^{3}\right)$ [34] In a university hospital from Greece, the highest mean total microbial load $\left(689 \mathrm{CFU} / \mathrm{m}^{3}\right)$ and the highest Gram-negative bacteria load $\left(4.16 \mathrm{CFU} / \mathrm{m}^{3}\right)$ were observed in the intensive medicine ward [35]. A study dedicated to hospitals in the USA observed a mean bacterial load of $720 \mathrm{CFU} / \mathrm{m}^{3}$ [36]. Some of the analyzed articles did not quantify the bacterial contamination found (5 out of 13 ).

\subsubsection{Seasonal Variation}

Peak values of airborne bacteria occurred in November and May, and the lowest values were recorded between December and February [34], not specifying the month. Park et al. [36] concluded that winter was shown to have a lower bacterial concentration (mean) $230 \mathrm{CFU} / \mathrm{m}^{3}$ (14 samples), while summer had the highest, $970 \mathrm{CFU} / \mathrm{m}^{3}$ (25 samples). Considering the effect of the time of day, studies suggested that the concentrations in the morning $(9 \mathrm{~h})$ ranged between $267.1-505.6 \mathrm{CFU} / \mathrm{m}^{3}$ and in the afternoon $(13 \mathrm{~h})$, 
213.6-410.9 CFU $/ \mathrm{m}^{3}$ [34]. In another hospital the main concentration of bacteria was found during service hours $\left(8 \mathrm{~h}-18 \mathrm{~h}\right.$ ) with an average of $930 \mathrm{CFU} / \mathrm{m}^{3}$ [36].

In the waiting rooms of primary healthcare units and hospital wards [37], mesophilic bacteria were the highest at $297 \mathrm{CFU} / \mathrm{m}^{3}$ in autumn. Airborne Staphylococci peaked at $96 \mathrm{CFU} / \mathrm{m}^{3}$ in winter (cardiology ward and intensive care room). The concentration of airborne actinomycetes was $231 \mathrm{CFU} / \mathrm{m}^{3}$ in winter (children's ward).

\subsubsection{Prevalent Bacteria}

Several studies reported the variability of prevalent bacteria in hospital settings. For example, a gynecology theatre from a hospital in Italy [38] presented the highest bacterial load of $261.3 \pm 131.3 \mathrm{CFU} / \mathrm{dm}^{2} / \mathrm{h}$, with a prevalence of Pseudomonas spp. $(25.8 \%)$, and the ophthalmology theatre had the highest concentration of microbial pathogens (38.9\%), being $22 \%$ of Pseudomonas species and $18.7 \%$ of Bacillus spp. [38]. In other hospital wards and operating theatres [39], the bacterial concentration ranged from $1.27 \times 10^{4}$ to $17.83 \times 10^{4} \mathrm{CFU} / \mathrm{dm}^{2} / \mathrm{h}$.

In an Italian hospital [40], the group of workers with the highest number of infections by H. pylori were physicians (16 out of 47) and nurses (18 out of 45). Both groups worked in the endoscopy unit; nurses (30 out of 75) worked in direct contact with patients but did not work in the endoscopy unit.

In terms of prevalent bacteria found in the air, the most mentioned was Escherichia coli, found in patients on a ward [34] in a Pakistan hospital [41] and in operating beds in Uganda [38]. Additionally, Pseudomonas aeruginosa was reported in the air of a hospital ward [34] in a Tehran teaching hospital [32], and in patients from a Pakistan hospital [41], in the gynecology theatre, main operating theatre, and on the instrument trolley. Pseudomonas spp. showed a higher prevalence, even though the species were not specified [38]. S. aureus were another common bacteria species found in patients from a Pakistan hospital [41], on the door handles of a Ugandan operating theatre [38], and in several wards in a Tehran hospital [32]. Staphylococcus spp. was detected in the air from a university hospital in Greece [35], in a Ugandan operating theatre [38] and in primary healthcare units and hospital wards in Poland [37]. Micrococcus luteus was found in the female surgery and male surgery wards in an Iranian hospital [39] and in a Brazilian hospital [33]. Other bacteria were mentioned, such as H. pylori [40], Staphylococcus epidermidis, Micrococcus, Streptococcus Flavobacterium spp., Acinetobacter calcoaceticus, Pantoea agglomerans, Enterobacter spp., Klebsiella oxytoca, Branhamella catarrhalis and Neisseria flavescens, Arthrobacter spp., Brevibacterium spp [34], Clostridium difficile [42], Gram-negative bacilli (XDR-GNB) [43], Haemophilus influenzae [41], Bacillus spp. [38], Staphylococcus epidermidis, Streptococcus spp., Diphtheroid spp., Micrococcus roseus, Bacillus subtilis. [39], mesophilic bacteria, airborne actinomycetes, S. saprophyticus, S. warneri [37], S. haemolyticus and S. hominis [33], Acinetobacter lwoffii, Salmonella typhimuriu and Klebsiella pneumonia [32].

\subsubsection{Health Effects}

Regarding health effects, the most prevalent bacteria-associated effects were hospitalacquired infections caused by Gram-positive bacteria and antibiotic-resistant Gram-negative bacteria [34,43], followed by nosocomial diarrhea caused by Clostridium difficile [42,44], nosocomial infections, and infections in immunocompromised people [33,37]. The other infections reported were bloodstream infections [33]; osteoarticular infections [41]; respiratory and infection diseases [36]; allergenic properties [34]; chronic active gastritis; gastric and duodenal ulcers [40]; osteomyelitis [41]; bacteremia; infections of skin, bones and joints; endocarditis; and central venous catheter infection [33]. 
Table 2. Information obtained from the articles selected.

\begin{tabular}{|c|c|c|c|c|c|c|c|c|c|}
\hline & Title & Country & $\begin{array}{c}\text { Analyzed } \\
\text { Environment }\end{array}$ & Collected Data & Results & Bacteria Found & Health Effects & Affected Population & References \\
\hline 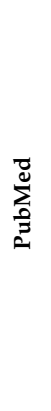 & $\begin{array}{c}\text { Does Hospital Work } \\
\text { Constitute a Risk } \\
\text { Factor for } \\
\text { Helicobacter Pylori } \\
\text { Infection? }\end{array}$ & Italy & Hospital & $\begin{array}{l}\text { A questionnaire was } \\
\text { completed by } \\
\text { participants before } \\
\text { collection of fecal } \\
\text { specimens. }\end{array}$ & $\begin{array}{l}249 \text { workers tested } \\
\text { positive for H. pylori.: } 16 \\
\text { out of } 47 \text { physicians } \\
\text { (endoscopy unit); } 18 \text { out } \\
\text { of } 45 \text { nurses (endoscopy } \\
\text { unit); } 5 \text { out of } 30 \\
\text { physicians (only contact } \\
\text { with patients); } 30 \text { out of } 75 \\
\text { nurses (only contact with } \\
\text { patients); } 9 \text { out of } 52 \\
\text { healthcare personnel (no } \\
\text { patient contact). }\end{array}$ & H. pylori & $\begin{array}{l}\text { Helicobacter pyloriinfection } \\
\text { likely represents the most } \\
\text { common bacterial infection of } \\
\text { the humanan species, with a } \\
\text { prevalence of } 25-50 \% \text { in } \\
\text { developed countries and up to } \\
90 \% \text { in developing countries. A } \\
\text { vast body of evidence now } \\
\text { indicates that H.pylori is the } \\
\text { principal etiological agent of } \\
\text { chronic active gastritis, as well } \\
\text { as gastric and duodenal ulcers, } \\
\text { and represents a major risk } \\
\text { factor for the development of } \\
\text { gastric cancer. }\end{array}$ & Workers & [40] \\
\hline $\begin{array}{l}\sum_{0}^{J} \\
\sum_{0}^{0} \\
\text { Dू }\end{array}$ & $\begin{array}{c}\text { Variability of } \\
\text { Airborne Microflora } \\
\text { in a Hospital Ward } \\
\text { Within a Period of } \\
\text { One Year }\end{array}$ & Poland & Hospital (ward) & Air samples & $\begin{array}{l}\text { Concentrations of } \\
\text { airborne bacteria: } \\
\text { 257.1-436.3 CFU / } \mathrm{m}^{3} \\
\text { peak values-November } \\
\text { and May, lowest } \\
\text { values-December to } \\
\text { February; Gram-positive } \\
\text { cocci: } 31.4-46.4 \% \% \text { of the } \\
\text { total count and } 37.2-49.6 \% \\
\text { of the respirable fraction; } \\
\text { Gram-negative bacteria: } \\
11.8-27.5 \% \text { of the total } \\
\text { count and } 5.6-30.2 \% \text { of } \\
\text { the respirable fraction. }\end{array}$ & $\begin{array}{l}\text { Staphylococcus } \\
\text { epidermidis, } \\
\text { Micrococcus, } \\
\text { Streptococcus } \\
\text { Flavobacterium spp., } \\
\text { emphAcinetobacter } \\
\text { calcoaceticus, } \\
\text { Pantoea } \\
\text { agglomerans, } \\
\text { Escherichia coli, } \\
\text { Enterobacter spp., } \\
\text { Klebsiella oxytoca, } \\
\text { Pseudomonas, } \\
\text { aeruy inosa, } \\
\text { Branhamella catarrhalis } \\
\text { and Neisseria } \\
\text { flavescers, } \\
\text { Arthrobacter spp., } \\
\text { Brevibacterium spp. }\end{array}$ & $\begin{array}{l}\text { The risk of exposure to } \\
\text { Staphylococci was diminished by } \\
\text { the fact that the isolated strains } \\
\text { were coagulase-negative and } \\
\text { unlikely to cause infections. } \\
\text { Gram-negative bacteria found } \\
\text { in the air of the hospital ward } \\
\text { could be a source of adverse } \\
\text { endotoxin, and Acinetobacter } \\
\text { strains may be a potential cause } \\
\text { of hospital infections } \\
\text { transmitted by air. Some of the } \\
\text { Gram-positive isolates } \\
\text { belonging to corynebacteria and } \\
\text { actinomycetes Arthrobacter spp., } \\
\text { Brevibacterium spp., Streptomyces } \\
\text { albus) show allergenic } \\
\text { properties. }\end{array}$ & Patients & [34] \\
\hline $\begin{array}{l}\sum_{0}^{J} \\
\sum_{0}^{0}\end{array}$ & $\begin{array}{l}\text { Clostridium Difficile } \\
\text { Infection in } \\
\text { Hospitalized } \\
\text { Children in the } \\
\text { United States }\end{array}$ & United States & Hospital & $\begin{array}{l}\text { Data were obtained } \\
\text { from the triennial } \\
\text { Healthcare Cost and } \\
\text { UUtilization Project } \\
\text { Kids' Inpatient } \\
\text { Database } \\
\text { (HCUP-KID) }\end{array}$ & $\begin{array}{c}\text { Clostridium difficile } \\
\text { infections increased from } \\
3.565 \text { in } 1997 \text { to } 7.779 \text { in } \\
2006 ; \text { Clostridium difficile } \\
\text { infections had an } \\
\text { increased risk of death } \\
\text { with an adjusted odds } \\
\text { ratio }(95 \% \text { confidence } \\
\text { interval); } 1.20(1.01-1.43), \\
\text { colectomy; } 1.36 \\
(1.04-1.79), \text { longer length } \\
\text { of stay; } 4.34 \text { (3.97-4.83) } \\
\text { and higher charges; } 2.12 \\
\text { (1.98-2.26). }\end{array}$ & Clostridium difficile & $\begin{array}{l}\text { Clostridium difficile is a } \\
\text { Gram-positive, spore-forming, } \\
\text { anaerobic bacillus that can } \\
\text { colonize the gastrointestinal } \\
\text { tract and can lead to C C difficile } \\
\text { infection (CDI). CDI has a wide } \\
\text { variation of severity, ranging } \\
\text { from asymptomatic colonization } \\
\text { to severe diarrhea, } \\
\text { pseudomembranous colitis, } \\
\text { toxic megacolon, bowel } \\
\text { perforation, and death. }\end{array}$ & Patients (children) & [42] \\
\hline
\end{tabular}


Table 2. Cont.

\begin{tabular}{|c|c|c|c|c|c|c|c|c|c|}
\hline & Title & Country & $\begin{array}{c}\text { Analyzed } \\
\text { Environment }\end{array}$ & Collected Data & Results & Bacteria Found & Health Effects & Affected Population & References \\
\hline 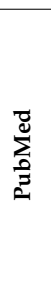 & $\begin{array}{l}\text { Trends in } \\
\text { Clostridium Difficile } \\
\text { Infection and Risk } \\
\text { Factors for Hospital } \\
\text { Acquisition of } \\
\text { Clostridium Difficile } \\
\text { Among Children } \\
\text { With Cancer }\end{array}$ & United States & Hospital & & & & $\begin{array}{l}\text { Clostridium difficile infection } \\
\text { (CDI) is the most common cause } \\
\text { of nosocomial diarrhea and can } \\
\text { lead to a range of complications } \\
\text { from colitis to toxic megacolon, } \\
\text { bowel perforation, and death. } \\
\text { CDI is a significant cause of } \\
\text { nosocomial and } \\
\text { antibiotic-associated diarrhea in } \\
\text { adults, with increasing } \\
\text { frequency and severity. }\end{array}$ & Patients (children) & [44] \\
\hline 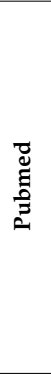 & $\begin{array}{l}\text { Assessment of the } \\
\text { Levels of Airborne } \\
\text { Bacteria, Gram- } \\
\text { Negative Bacteria, } \\
\text { and Fungi in } \\
\text { Hospital Lobbies }\end{array}$ & Korea & Hospital Lobbies & Air samples & $\begin{array}{c}\text { Mean level of airborne } \\
\text { bacteria: } \\
7.2 \times 10^{2} \mathrm{CFU} / \mathrm{m}^{3} ; \\
\text { service hours }(08 \mathrm{~h}-18 \mathrm{~h}): \\
9.3 \times 10^{2} \mathrm{CFU} / \mathrm{m}^{3}(\mathrm{mean}) ; \\
\text { after service hours } \\
(18 \mathrm{~h}-24 \mathrm{~h}): \\
4.4 \times 10^{2} \mathrm{CFU} / \mathrm{m}^{3} ; \\
\text { winter: } 2.3 \times 10^{2} \mathrm{CFU} / \mathrm{m}^{3} \\
\text { (mean); summer: } \\
9.7 \times 10^{2} \mathrm{CFU} / \mathrm{m}^{3} \\
\text { (mean); Gram- negative } \\
\text { bacteria mean: } \\
1.7 \times 10 \mathrm{CFU} / \mathrm{m}^{3} .\end{array}$ & & & All occupants & [36] \\
\hline 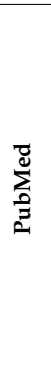 & $\begin{array}{l}\text { Risk Factors and } \\
\text { Outcomes of } \\
\text { Infections Caused by } \\
\text { Extremely } \\
\text { Drug-Resistant } \\
\text { Gram-Negative } \\
\text { Bacilli in Patients } \\
\text { Hospitalized in } \\
\text { Intensive Care Units }\end{array}$ & United States & ICUs & $\begin{array}{c}\text { A matched } \\
\text { case-control (1:2) } \\
\text { study was conducted } \\
\text { from February } 2007 \\
\text { to January } 2010 \text { in } 16 \\
\text { ICUs. }\end{array}$ & $\begin{array}{c}\text { An immunocompromised } \\
\text { state (OR }=1.55, p=0.047) \\
\text { and exposure to amikacin } \\
(\mathrm{OR}=13.81, p<0.001), \\
\text { levofloxacin }(\mathrm{OR}=2.05, \\
p=0.005), \text { or } \\
\text { trimethoprim- } \\
\text { sulfamethoxazole } \\
(\mathrm{OR}=3.42, p=0.009) \text { were } \\
\text { factors associated with } \\
\text { XDR-GNB HAIs. }\end{array}$ & $\begin{array}{c}\text { Extremely } \\
\text { drug-resistant } \\
\text { Gram-negative bacilli } \\
\text { (XDR-GNB) }\end{array}$ & $\begin{array}{c}\text { Antibiotic-resistant, } \\
\text { Gram-negative bacilli (GNB) are } \\
\text { increasingly common causes of } \\
\text { healthcare-associated infections } \\
\text { (HAIs) in intensive care units } \\
\text { (ICUs) and are associated with } \\
\text { higher mortality rates, longer } \\
\text { hospitalizations, and increased } \\
\text { healthcare expenditures. } \\
\text { Effective treatment for } \\
\text { extremely drug-resistant (XDR) } \\
\text { GNB infections is challenging } \\
\text { because of limited therapeutic } \\
\text { options. }\end{array}$ & Patients & [43] \\
\hline 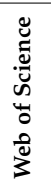 & $\begin{array}{l}\text { Staph Aureus as the } \\
\text { most commonon cause } \\
\text { of osteoarticular } \\
\text { infection in Dost-1 } \\
\text { Mayo Hospital, } \\
\text { Lahore }\end{array}$ & Pakistan & Hospital & $\begin{array}{l}\text { Patients were } \\
\text { followed up in OPD } \\
\text { for } 24 \text { weeks post } \\
\text { operatively to assess } \\
\text { the outcome of the } \\
\text { procedure }\end{array}$ & $\begin{array}{l}\text { Causative organism (200 } \\
\text { patients): Staph Aureus in } \\
96 \% \text { of the patients, } \\
\text { Haemophilus influenzae } \\
1.2 \% \text {, Escherichia Coli was } \\
2 \% \text { and Pseudomonas } \\
\text { Aeruginosa was } 0.8 \% \text {. }\end{array}$ & $\begin{array}{l}\text { Staph Aureus, } \\
\text { Heamophilus } \\
\text { influenzae, Escherichia } \\
\text { Coli, Pseudomonas } \\
\text { Aeruginosa }\end{array}$ & $\begin{array}{l}\text { Staph Aureus was the organism } \\
\text { which caused osteoarticular } \\
\text { infection in } 96 \% \text { of patients. }\end{array}$ & Patients & [41] \\
\hline
\end{tabular}


Table 2. Cont.

\begin{tabular}{|c|c|c|c|c|c|c|c|c|c|}
\hline & Title & Country & $\begin{array}{c}\text { Analyzed } \\
\text { Environment }\end{array}$ & Collected Data & Results & Bacteria Found & Health Effects & Affected Population & References \\
\hline 茕 & $\begin{array}{l}\text { Air Contamination in } \\
\text { Different } \\
\text { Departments of a } \\
\text { Tertiary Hospital. } \\
\text { Assessment of } \\
\text { Microbial Load and } \\
\text { of Antimicrobial } \\
\text { Susceptibility }\end{array}$ & Greece & University hospital & Air samples & $\begin{array}{l}\text { The highest mean total } \\
\text { microbial load was } \\
\text { observed in the IMW } \\
\left(6899 \mathrm{~m}^{3}\right), \text {, followed by the } \\
\mathrm{SW}\left(596 \mathrm{CFU} / \mathrm{m}^{3}\right) \text {, the } \\
\mathrm{NU}\left(509 \mathrm{CFU} / \mathrm{m}^{3}\right) \text { and, } \\
\text { finally, the ICU } \\
\left(353 \mathrm{CFU} / \mathrm{m}^{3}\right) \text {. The load } \\
\text { of } \mathrm{GN} \text {, the highest load, } \\
\text { was observed in the IMW } \\
\left(4.16 \mathrm{CFU} / \mathrm{m}^{3}\right) \text {, followed } \\
\text { by the ICU }(1.14 \\
\left.\mathrm{CFU} / \mathrm{m}^{3}\right) \text {, the SW } \\
\left(0.83 \mathrm{CFU} / \mathrm{m}^{3}\right) \text {, and the } \\
\mathrm{NU}\left(0.81 \mathrm{CFU} / \mathrm{m}^{3}\right) \text {. }\end{array}$ & $\begin{array}{c}\text { In total, } 101 \text { samples } \\
\text { were collected, from } \\
\text { which } 158 \\
\text { Gram-positive (GP) } \\
\text { and } 44 \\
\text { Gram-negative (GN) } \\
\text { strains were isolated. } \\
\text { The majority of GP } \\
\text { isolates were } \\
\text { Staphylococcus spp. } \\
\text { (n= } 100) \text {. The highest } \\
\text { total microbial load } \\
\text { was reported in the } \\
\text { IMW ( } p=0.005) \text {, } \\
\text { while the highest } \\
\text { Staphylococcus load } \\
\text { was observed in the } \\
\text { ICU }(p=0.018) \text {. }\end{array}$ & & All occupants & [35] \\
\hline 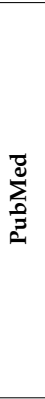 & $\begin{array}{c}\text { Contamination of } \\
\text { Microbial Pathogen } \\
\text { and Their } \\
\text { Antimicrobial Pattern } \\
\text { in Operating } \\
\text { Theatres of Peri- } \\
\text { Urban Eastern } \\
\text { Uganda: A } \\
\text { Cross-Sectional } \\
\text { Study }\end{array}$ & Uganda & Operating theatre & $\begin{array}{c}109 \text { samples }(\mathrm{n}=31 \\
\text { air samples and } \\
\mathrm{n}=78 \text { swabs })\end{array}$ & $\begin{array}{c}\text { Gynecology } \\
\text { theatre-261.3 } 131.3 \\
\text { CFU/dm2/h } \\
\text { (Pseudomonas } \\
\text { spp--25.8\%); main } \\
\text { OT-69.5 } \pm 78.7-38.9 \% \\
\text { microbial pathogens } \\
\text { (Pseudomonas spp.-22\%; } \\
\text { Bacillus spp.-18.7\%); } \\
\text { operating bed (E. coli } \\
\text {-77.8\%), instrument trolley } \\
\text { (Pseudomonas } \\
\text { sp.-28.6\%), door } \\
\text { handles (100\% of } \\
\text { S. aureus) }\end{array}$ & $\begin{array}{l}\text { Pseudomonas spp., } \\
\text { coagulase negative } \\
\text { staphylococcus, } \\
\text { Bacillus spp., E. coli, } \\
\text { Staphylococcus aureus }\end{array}$ & & Patients & [38] \\
\hline 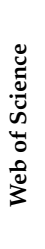 & $\begin{array}{l}\text { Assessment of } \\
\text { bioaerosol particle } \\
\text { characteristics at } \\
\text { different hospital } \\
\text { wards and operating } \\
\text { theatres: A case } \\
\text { study in Tehran }\end{array}$ & Iran & $\begin{array}{l}\text { Hospital (CCU, } \\
\text { GICU, ICU, NICU, } \\
\text { OT, NS) }\end{array}$ & $\begin{array}{l}\text { Passive sampling } \\
\text { method (252 plates) }\end{array}$ & $\begin{array}{l}\text { Concentration of bacterial: } \\
\text { 127 to } 1783 \text { CFUm-2 h-1; } \\
\text { Micrococcus luteus: NS } \\
(41.5 \%), \text { WS S (72.3\%), MS } \\
\text { (70.0\%), ICU (66.2\%); } \\
\text { Staphylococcus pidermidis: } \\
\text { GICU (46.6\%, NICU } \\
\text { (50.0\%); CCU: } \\
\text { Streptococcus spp. } 53.8 \%), \\
\text { Micrococcus luteus }(46.2 \%) \text {. }\end{array}$ & $\begin{array}{l}\text { Micrococcus luteus, } \\
\text { Staphylococcus } \\
\text { epidermidis, } \\
\text { Streptococcus spp., } \\
\text { Diphtheroid spp., } \\
\text { Micrococcus roseus, } \\
\text { Bacillus subtilis. }\end{array}$ & & All occupants & [39] \\
\hline
\end{tabular}


Table 2. Cont.

\begin{tabular}{|c|c|c|c|c|c|c|c|c|c|}
\hline & Title & Country & $\begin{array}{c}\text { Analyzed } \\
\text { Environment }\end{array}$ & Collected Data & Results & Bacteria Found & Health Effects & Affected Population & References \\
\hline $\begin{array}{l}\sum_{0}^{\circ} \\
\vdots \\
\vdots \\
\vdots\end{array}$ & $\begin{array}{l}\text { Assessment of } \\
\text { Microbiological } \\
\text { Aerosol } \\
\text { Concentration in } \\
\text { Selected Healthcare } \\
\text { Facilities in Southern } \\
\text { Poland }\end{array}$ & Poland & $\begin{array}{l}\text { Primary healthcare } \\
\text { units and hospital } \\
\text { wards }\end{array}$ & Air samples & $\begin{array}{c}\text { Mesophilic bacteria } \\
\text { ranged } 5 \mathrm{CFU} / \mathrm{m}^{3} \text { in } \\
\text { winter } \\
\text { (No. IV)-297 CFU } / \mathrm{m}^{3} \text { in } \\
\text { autumn (No. V); airborne } \\
\text { Staphylococci ranged } 1 \\
\mathrm{CFU} / \mathrm{m}^{3} \text { in spring-96 } \\
\mathrm{CFU} / \mathrm{m}^{3} \text { in winter (both } \\
\text { No. IX); airborne } \\
\text { actinomycetes ranged } 7 \\
\mathrm{CFU} / \mathrm{m}^{3} \text { in spring and } \\
\text { autumn (No. IV)-231 } \\
\mathrm{CFU} / \mathrm{m}^{3} \text { in winter (No. } \\
\mathrm{VIII);} 55 \text { isolates strains of } \\
\text { Staphylococcus spp.: S. } \\
\text { saprophyticus } 25 \% \text {. (14)), S. } \\
\text { warneri } 24 \% \text {. (13). }\end{array}$ & $\begin{array}{l}\text { Mesophilic Bacteria, } \\
\text { Airborne staphylococci, } \\
\text { Airborne actinomycetes, } \\
\text { Staphylococus spp., S. } \\
\text { saprophyticus, } S . \\
\text { warneri }\end{array}$ & $\begin{array}{l}\text { Nosocomial infections and } \\
\text { infections in } \\
\text { immunocompromised people. }\end{array}$ & All occupants & [37] \\
\hline 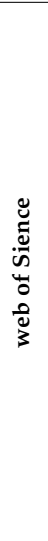 & $\begin{array}{c}\text { Potentially } \\
\text { pathogenic bacteria } \\
\text { isolated from } \\
\text { neglected air and } \\
\text { surfaces in hospitals }\end{array}$ & Brazil & Hospital & $\begin{array}{l}\text { Air samples, surfaces } \\
\text { and uniforms } \\
\text { samples }\end{array}$ & $\begin{array}{l}\text { The highest microbial } \\
\text { load was found in the } \\
\text { PSRR (566 CFU } / \mathrm{m}^{3} \\
\text { Hospital B) and the lowest } \\
\text { in the ORT (124.5 } \\
\text { CFU } / \mathrm{m}^{3} \text {, Hospital B). }\end{array}$ & $\begin{array}{l}\text { In the aerial } \\
\text { microbiota of the } \\
\text { sampled areas of } \\
\text { both hospitals, } M \text {. } \\
\text { luteus, S. haemolyticus } \\
\text { and S. hominis spp. } \\
\text { hominis were the } \\
\text { prevalent } \\
\text { microorganisms, } \\
\text { with a percentage } \\
\text { greater than } 30 \% \text {. On } \\
\text { the surfaces and } \\
\text { uniforms, there was a } \\
\text { prevalence of } M \text {. } \\
\text { luteus ( } 40 \% \text { ) and } S \text {. } \\
\text { hominis spp hominis } \\
(20 \%) \text {. }\end{array}$ & $\begin{array}{l}\text { S. hominis subsp. hominis is } \\
\text { reported as a potential pathogen } \\
\text { isolated in generalized } \\
\text { infections. M. luteeus, found in } \\
\text { several sampled environments, } \\
\text { is described as the causative } \\
\text { agent in endocarditis and } \\
\text { central venous catheter infection. } \\
\text { Some microorganisms, isolated } \\
\text { in low percentages in this study, } \\
\text { are described in some cases of } \\
\text { nosocomial infections, as is the } \\
\text { case of } E \text {. ludvwigii, reported as } \\
\text { an agent causing an outbreak of } \\
\text { bloodstream infection. Bacillus } \\
\text { cereus causes bacteremia, } \\
\text { infection of skin, bones and } \\
\text { joints; S. lugdunensis causes } \\
\text { bacterema. S. voarneri causes } \\
\text { endocarditis and S. cohnii subsp. } \\
\text { urealyticus causes bacteremia. }\end{array}$ & All occupants & [33] \\
\hline
\end{tabular}


Table 2. Cont.

\begin{tabular}{|c|c|c|c|c|c|c|c|c|c|}
\hline & Title & Country & $\begin{array}{c}\text { Analyzed } \\
\text { Environment }\end{array}$ & Collected Data & Results & Bacteria Found & Health Effects & Affected Population & References \\
\hline 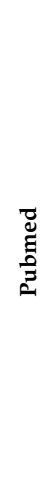 & $\begin{array}{l}\text { Assessment of } \\
\text { Bacterial Pathogens } \\
\text { and their Antibiotic } \\
\text { Resistance in the Air } \\
\text { of Different Wards of } \\
\text { Selected Teaching } \\
\text { Hospitals in Tehran }\end{array}$ & Tehran & $\begin{array}{l}\text { Wards of selected } \\
\text { two teaching } \\
\text { hospitals }\end{array}$ & Air samples & $\begin{array}{l}\text { The median level of } \\
\text { colonies in the wards of } \\
\text { hospital } 1 \text { was } 129.87 \\
(87.46-268.97) \mathrm{CFU} / \mathrm{m}^{3} \\
\text { and } 297.97 \text { (217.66- } 431.85) \\
\text { CFU } / \mathrm{m}^{3} \text { for hospital } 2 .\end{array}$ & $\begin{array}{l}\text { Staphylococcus aureus } \\
\text { was identified in } \\
\text { most wards of the } \\
\text { tow hospital. } \\
\text { Acinetobacterlyoffii } \\
\text { and Salmonellai } \\
\text { typhimiriuu were the } \\
\text { most abundant and } \\
\text { least Gram-negative } \\
\text { bacteria in hospital 1, } \\
\text { respectively. In } \\
\text { hospital 2, } \\
\text { Pseudomonas } \\
\text { aeuringos and } \\
\text { Klebsiella pneumonia } \\
\text { were the most } \\
\text { abundant } \\
\text { Gram-negative } \\
\text { bacteria in the } \\
\text { sampling stations. }\end{array}$ & & All occupants & [32] \\
\hline
\end{tabular}




\section{Discussion}

Numerous studies presented divergent points of view on how bacterial contamination can be observed in different locations within hospital facilities, how seasonal variations affect the concentration, and even how data regarding the most prevalent genera that can be found in healthcare environments and staff due to occupational activities.

In the first presented study [34], concentrations of airborne bacteria reached a peak in November $\left(436.3 \mathrm{CFU} / \mathrm{m}^{3}\right)$, and the lowest value was identified in December $\left(257.1 \mathrm{CFU} / \mathrm{m}^{3}\right)$. However, the authors did not explain the decrease between these two months or between the other months of the year that were assessed. Another study, conducted in Portugal [45], described that most of the departments analyzed presented a high level of bacterial concentration (ranging from 12 to $170 \mathrm{CFU} / \mathrm{m}^{3}$ ) and concluded that the indoor bacterial concentration was not influenced by outdoor concentration but by indoor air. A higher bacterial concentration was identified in the mornings $\left(267.1-505.6 \mathrm{CFU} / \mathrm{m}^{3}\right)$, and even though the authors did not provide an explanation, we hypothesize that this could be due to increased human activity from visitors or workers [36,46].

In another analyzed study [37], winter and autumn had the highest concentration levels of bacteria with the increased bioburden associated with the waiting room in autumn and children's ward in the winter. A possible explanation for the higher load in the waiting room can be attributed to an increase in the number of occupants (200 per day or more). The same hypothesis is suggested in the children's ward, with the additional factor of the increased number of infections in children during the wintertime. The fact that the rooms in that ward are small, and that more than one parent can accompany the child, is another factor that increases the concentration of bacteria such as airborne actinomycetes, which were the most prevalent in the children's ward [37].

The data from Portuguese studies revealed that Staphylococcus epidermidis [45] and Micrococcus spp. [45-47] were the most prevalent bacteria identified. However, S. epidermidis is not considered to be a relevant risk of exposure due to its lower infections rates [34]. On the other hand, Acinetobacter (species not identified) was found in two studies [32,34] as a prevalent genus in a university hospital from Ethiopia, justifying its persistence due to its great survival ability in the indoor environment [47], which can be a potential cause for hospital infections transmitted via the air [48]. Another relevant microorganism is Pantoea agglomerants, which is able to infect hospitalized individuals, particularly immunodeficient patients, through contaminated medical instruments [49].

A bacteria genus described in several studies considered of great interest is Staphylococcus spp., which was identified at the highest concentration in a cardiology ward/intensive care room (hospital 5). Once the strains were analyzed, S. saprophyticus was the most predominant, followed by $S$. warneri, being reported as an important opportunistic pathogen and associated with healthcare-acquired infections [37]. Cabo Verde et al. [45] also found S. warneri to be a prevalent species in the hospital, but no data were reported regarding S. saprophyticus in contrast to the findings of Sivagnanasundaram et al. [50]. S. saprophyticus can infect an individual's blood through catheters, surgical prostheses, pneumonia, urinary tract infections and more [51-53]; therefore, this species is of particular relevance. Moreover, Staphylococcus aureus is one of the most relevant nosocomial pathogens, described as one of the main pathogenic bacteria that cause osteomyelitis (including in children)[54-59] septic arthritis [60-63], and prosthetic joint infections [64-67]. S. aureus is a commensal bacterium and a human pathogen; about $30 \%$ of all humans are colonized with S. aureus [68]. Osteoarticular infections can occur by the direct inoculation of microorganisms into tissues due to penetrating or open trauma [69]. In limited settings, infections complicate as many as $44 \%$ of open fractures [69]. Trauma-related osteoarticular infections among patients with punctures wounds seeking medical care varied from 2-60\% depending on the type of the injury [70-72]. S. aureus was also prevalent in the studies by Matinyi et al. [38] and Thomas et al. [73], being detected on door handles, which could be considered a possible source of nosocomial infection [38]. Additionally, Staphylococcus epidermidis, as well as Micrococcus luteus and Bacillus subtilis, were common in the studies by Sivagnanasundaram et al. [50], 
Bielawska-Drózd et al. [74], and Bolookat et al. [39]. The reason for these results could be related to the presence of these bacteria in the skin, mucous membranes, hair of human beings and animals [75-78].

Considering health effects, the identification of Clostridium difficile, a Gram-positive, anaerobic, spore-forming bacillus, must be considered, as it is the principal agent of pseudomembranous colitis in humans [79]. In the hospital setting, C. difficile infection is the main cause of healthcare-associated diarrhea [80]. Symptoms arise when C. difficile spores germinate in the intestine, and the bacteria start to produce toxins, Toxin A (TcdA) and Toxin B (TcdB), causing the inflammation of the large intestine [81]. The clinical presentation can range from mild diarrhea to lethal toxic megacolon [81]. Nonetheless, the ingestion of C. difficile spores does not always lead to the development of symptomatic disease, since this bacterium can be silently present in the intestine without manifesting any symptoms, denominated as asymptomatic $C$. difficile colonization [82]. However, the patients with this condition act as a reservoir for further transmissions [83,84], and they can progress to the infection themselves, especially if they are affected by an underlying illness [85]. The infection is transmitted by spores that are environmentally resistant [86].

Another microorganism of interest is H. pylori, which is associated with occupational exposure among endoscopy personnel [87]. The study by Mastromarino et al. [40] aimed to determine if different staff groups of healthcare workers, either with or without direct patient contact, were at equal risk of acquiring $H$. pylori infection. The authors concluded that direct contact with patients is an important factor for becoming infected, as opposed to simply working in the endoscopy unit. Another study highlighted [87] that $24 \%$ (9 out of 37) of gastrointestinal endoscopy personnel, and 47\% (33 out of 70) of workers in a hospital who care for disabled individuals, tested positive for $H$. pylori. In this case, direct contact with patients and working in a hospital where disabled individuals reside was associated with $H$. pylori infections, but the exposure to gastrointestinal secretions of the patients was not [87]. This study supports the previous study's idea that direct contact with patients is a factor to take into consideration.

Among Gram-negative bacteria, the most frequently identified pathogens are Escherichia coli, Klebsiella pneumoniae, Pseudomonas aeruginosa, and Acinetobacter baumannii. E.coli was described to be prevalent in operating beds due to fecal contamination and the lack of efficiency in the cleaning process [88,89]. Pseudomonas spp., one of the most significant genera of nosocomial pathogens, was the most prevalent bacteria in all operating theatres in the Matinyi et al. study [38], and was identified in other studies [73,90] that referred to antiseptic solutions as a possible source of this contamination [56,57,91,92]. Other bacteria, Bacillus spp., can be related to dusty environments, the type commonly found in Uganda [38]. This contamination might occur in indoor areas if the windows are open for natural ventilation and could then be transferred to the operating theatres [73]. Furthermore, $A$. baumannii was associated with a vast number of infections, such as those of the bloodstream, respiratory tract, surgical sites, and urinary tract [93]. Transmission between patients in hospital settings is difficult to prevent because of the bacterium's capacity to persist in the environment, particularly in intensive care units [93]. These Gram-negative pathogens are associated with the etiology of numerous and severe hospitalacquired infections in humans and have the capacity to resist antimicrobial agents, which has become an increasingly relevant problem [94]. Currently, antimicrobial-resistant Gramnegative bacteria are expanding worldwide and are considered a significant threat to human health [3].

\section{Conclusions}

The bacterial contamination of healthcare units was found to be diverse and causative of several hazardous health effects. The reported contamination in this setting was divergent depending mostly on the sampling site. Nevertheless, Pseudomonas spp. and Staphylococcus spp., two of the greatest nosocomial pathogens, were the most prevalent bacteria identified in healthcare units. Hospital-acquired infection caused by Gram-positive 
bacteria and antibiotic-resistance, Gram-negative bacteria were the most frequent and relevant associated health effects. The necessity for tight control in the cleaning process was made clear in order to improve disinfection efficiency in wards, surfaces, equipment, and uniforms and prevent direct contact transmission. A better understanding of seasonal variations is essential, allowing hospitals to avoid contamination peaks.

Supplementary Materials: The following supporting information can be downloaded at: https: / / www.mdpi.com/article/10.3390/app12041958/s1, Table S1: PRISMA Checklist (Adopted from Moher et al. $2009 *$ ).

Author Contributions: Conceptualization, A.M. Data curation, A.M., J.C., N.G.; Formal analysis, A.M., J.C. N.G., C.V., S.C.V., A.S.-U.; Investigation, A.M., J.C., N.G.; Methodology, A.M., S.C.V., A.S.-U.; Supervision, A.M; Validation, A.M., C.V., S.C.V., A.S.-U.; Writing-original draft, A.M., J.C., N.G.; Writing-review and editing, A.M., E.R., C.V., S.C.V., A.S.-U. All authors have read and agreed to the published version of the manuscript.

Funding: This work was supported of FCT/MCTES through UIDB/05608/2020 and UIDP/05608/2020. And by C2TN/IST (UIDB/04349/2020pUIDP/04349/2020).

Institutional Review Board Statement: Not applicable.

Informed Consent Statement: Not applicable.

Data Availability Statement: Not applicable.

Acknowledgments: H\&TRC authors gratefully acknowledge the national support of FCT/MCTES through UIDB/05608/2020 and UIDP/05608/2020. The support of FCT is also acknowledged by C2TN/IST (UIDB/04349/2020pUIDP/04349/2020).

Conflicts of Interest: The authors declare no conflict of interest.

\section{References}

1. Humphreys, H.; Smyth, E.T.M. Prevalence surveys of healthcare-associated infections: What do they tell us, if anything? Clin. Microbiol. Infect. 2006, 12, 2-4. [CrossRef] [PubMed]

2. World Health Organization. Health Care-Associated Infections Fact Sheet. 2013. Available online: http://www.who.int/gpsc/ country_work/gpsc_ccisc_fact_sheet_en.pdf (accessed on 10 September 2021).

3. National Nosocomial Infections Surveillance System. National Nosocomial Infections Surveillance (NNIS) system report, data summary from January 1992 through June 2004, issued October 2004. Am. J. Infect. Control 2004, 32, 470. [CrossRef]

4. Menachemi, N.; Yeager, V.A.; Welty, E.; Manzella, B. Are physician productivity and quality of care related? J. Healthc. Qual. 2015, 37, 93-101. [CrossRef] [PubMed]

5. Haque, M.; Sartelli, M.; McKimm, J.; Abu Bakar, M. Health care-associated infections-An overview. Infect. Drug Resist. 2018, 11, 2321-2333. [CrossRef] [PubMed]

6. Levy, S.B. Factors impacting on the problem of antibiotic resistance. J. Antimicrob. Chemother. 2002, 49, 25-30. [CrossRef] [PubMed]

7. National Academies of Sciences, Engineering and Medicine. Microbiomes of the Built Environment: A Research Agenda for Indoor. Microbiology, Human Health, and Buildings; The National Academies Press: Washington, DC, USA, 2017; pp. 95-131.

8. Qudiesat, K.; Abu-Elteen, K.H.; Elkarmi, A.Z.; Hamad, M.; Abussaud, M. Assessment of airborne pathogens in healthcare settings. Afr. J. Microbiol. Res. 2009, 3, 66-76. Available online: https://www.academicjournals.org/ajmr (accessed on 10 October 2021).

9. Marchand, G.; Duchaine, C.; Lavoie, J.; Veillette, M.; Cloutier, Y. Bacteria emitted in ambient air during bronchoscopy-A risk to health care workers? Am. J. Infect. Control 2016, 44, 1634-1638. [CrossRef] [PubMed]

10. Douwes, J.; Torne, P.; Pearce, N.; Heederik, D. Bioaerosol health effects and exposure assessment: Progress and prospects. Ann. Occup. Hyg. 2003, 47, 187-200. [CrossRef]

11. Cross, A.S. What is a virulence factor? Crit. Care 2008, 12, 196. [CrossRef]

12. Wu, H.J.; Wang, A.H.; Jennings, M.P. Discovery of virulence factors of pathogenic bacteria. Curr. Opin. Chem. Biol. 2008, 12, 93-101. [CrossRef]

13. Actor, J.A.J. 11-Basic Bacteriology. Elsevier's Integrated Review; Elsevier/Saunders: Philadelphia, PA, USA, 2012; pp. 93-103. [CrossRef]

14. Huslage, K.; Rutala, W.; Sickbert-Bennett, E.; Weber, D. A quantitative approach to defining "high-touch" surfaces in hospitals. Infect. Control Hosp. Epidemiol. 2010, 31, 850-853. [CrossRef] [PubMed]

15. Weber, D.; Rutala, W.; Miller, M.; Huslage, K.; Sickbert-Bennett, E. Role of hospital surfaces in the transmission of emerging health care-associated pathogens: Norovirus, Clostridium difficile, and Acinetobacter species. Am. J. Infect. Control 2010, 38, S25-S33. [CrossRef] [PubMed] 
16. Luksamijarulkul, P.; Aiempradit, N.; Vatanasomboon, P. Microbial Contamination on Used Surgical Masks among Hospital Personnel and Microbial Air Quality in their Working Wards: A Hospital in Bangkok. Oman Med. J. 2014, 29, 346-350. [CrossRef] [PubMed]

17. Drees, M.; Snydman, D.; Schmid, C.; Barefoot, L.; Hansjosten, K.; Vue, P.; Cronin, M.; Nasraway, S.; Golan, Y. Prior environmental contamination increases the risk of acquisition of vancomycin-resistant enterococci. Clin. Infect. Dis. 2008, 46, 678-685. [CrossRef]

18. Malamou-Ladas, H.; O'Farrell, S.; Nash, J.; Tabaqchali, S. Isolation of Clostridium difficile from patients and the environment of hospital wards. J. Clin. Pathol. 1983, 36, 88-92. [CrossRef] [PubMed]

19. Neely, A.; Maley, M. Survival of enterococci and staphylococci on hospital fabrics and plastic. J. Clinic. Microbiol. 2000, 38, 724-726. [CrossRef]

20. Shaughnessy, M.; Micielli, R.; DePestel, D.; Arndt, J.; Strachan, C.; Welch, K.; Chenoweth, C. Evaluation of hospital room assignment and acquisition of Clostridium difficile infection. Infect. Control Hosp. Epidemiol. 2011, 32, 201-206. [CrossRef]

21. Allegranzi, B.; Bagheri Nejad, S.; Combescure, C.; Graafmans, W.; Attar, H.; Pittet, D.L.D. Burden of endemic health-careassociated infection in developing countries: Systematic review and meta-analysis. Lancet 2011, 377, 228-241. [CrossRef]

22. Burke, J.P. Infection control-A problem for patient safety. N. Engl. J. Med. 2003, 348, 651-656. [CrossRef]

23. Goyer, N.; Lavoie, J.; Lazure, L.; Marchand, G. Bioaerosols in the Workplace: Evaluation, Control and Prevention Guide; Institut de Reserche en Santé et en Sécurité du Travail du Québec: Quebéc, QC, Canada, 2001.

24. Huff, W.; Kubena, L.; Harvey, R.; Doerr, J. Mycotoxin interactions in poultry and swine. J. Anim. Sci. 1988, 66, 2351-2355. [CrossRef]

25. Dizbay, M.; Tunccan, O.; Sezer, B.; Aktas, F.; Arman, D. Nosocomial Burkholderia cepacia infections in a Turkish university hospital: A five-year surveillance. J. Infect. Dev. Ctries. 2009, 3, 273-277. [CrossRef]

26. Gautam, V.; Singhal, L.; Ray, P. Burkholderia cepacia complex: Beyond pseudomonas and acinetobacter. Indian J. Med. Microbiol. 2011, 29, 4-12. [CrossRef]

27. Gautam, V.; Patil, P.; Kumar, S.; Midha, S.; Kaur, M.; Kaur, S.; Singh, M.; Mali, S.; Shastri, J.; Arora, A.; et al. Multilocus sequence analysis reveals high genetic diversity in clinical isolates of Burkholderia cepacia complex from India. Sci. Rep. 2016, 6, 35769. [CrossRef] [PubMed]

28. Paul, L.; Hegde, A.; Pai, T.; Shetty, S.; Baliga, S.; Shenoy, S. An Outbreak of Burkholderia cepacia Bacteremia in a Neonatal Intensive Care Unit. Indian J. Pediatr. 2016, 83, 285-288. [CrossRef] [PubMed]

29. Sousa, S.; Feliciano, J.; Pita, T.; Guerreiro, S.; Leitão, J.H. Burkholderia cepacia Complex Regulation of Virulence Gene Expression: A Review. Genes 2017, 8, 43. [CrossRef]

30. Antony, B.; Cherian, E.; Boloor, R.S.K. A sporadic outbreak of Burkholderia cepacia complex bacteremia in pediatric inten-sive care unit of a tertiary care hospital in coastal Karnataka, South India. Indian J. Pathol. Microbiol. 2016, 59, 197-199. [CrossRef] [PubMed]

31. Singhal, T.; Shah, S. Naik, R. Outbreak of Burkholderia cepacia complex bacteremia in a chemotherapy day care unit due to intrinsic contamination of an antiemetic drug. Indian J. Med. Microbiol. 2015, 33, 117-119. [CrossRef]

32. Montazer, M.; Soleimani, N.; Vahabi, M.; Abtahi, M.; Etemad, K.; Zendehdel, R. Assessment of Bacterial Pathogens and their Antibiotic Resistance in the Air of Different Wards of Selected Teaching Hospitals in Tehran. Indian J. Occup. Environ. Med. 2011, 25, 78-83. [CrossRef]

33. Oliveira, M.; Cunha, L.; Cruz, F.; Batista, N.; Gil, E.; Alves, V.; Bara, M.; Torres, I. Potentially pathogenic bacteria isolated from neglected air and surfaces in hospitals. J. Pharm. Sci. 2011, 57. [CrossRef]

34. Augustowska, M.; Dutkiewicz, J. Variability of airborne micro-flora in a hospital ward within a period of one year. AAEM 2006, 13, 99-106.

35. Tselebonis, A.; Nena, E.; Panopoulou, M.; Kontogiorgis, C.; Bezirtzoglou, E.; Constantinidis, T. Air Contamination in Different Departments of a Tertiary Hospital. Assessment of Microbial Load and of Antimicrobial Susceptibility. Biomedecines 2020, 8, 163. [CrossRef] [PubMed]

36. Park, D.; Yeom, J.; Lee, W.; Lee, K. Assessment of the levels of airborne bacteria, Gram-negative bacteria, and fungi in hospital lobbies. Int. J. Environ. Res. Public Health 2013, 10, 541-555. [CrossRef] [PubMed]

37. Stec, J.; Lenart-Boron, A. Assessment of microbiological aerosol concentration in selected healthcare facilities in southern Poland. Cent. Eur. J. Public Health 2019, 27, 239-244. [CrossRef] [PubMed]

38. Matinyi, S.; Enoch, M.; Akia, D.; Byaruhanga, V.; Masereka, E.; Ekeu, I.; Atuheire, C. Contamination of microbial pathogens and their an-timicrobial pattern in operating theatres of peri-urban eastern Uganda: A cross-sectional study. BMC Infect. Dis. 2018, 18, 460. [CrossRef]

39. Bolookat, F.; Hassanvand, M.S.; Faridi, S.; Hadei, M.; Rahmatinia, M.; Alimohammadi, M. Assessment of bioaerosol particle characteristics at different hospital wards and operating theaters: A case study in Tehran. MethodsX 2018, 5, 1588-1596. [CrossRef]

40. Mastromarino, P.; Conti, C.; Donato, K.; Strappini, P.; Cattaruzza, M.; Orsi, G. Does hospital work constitute a risk factor for Helicobacter pylori infection? J. Hosp. Infect. 2005, 60, 261-268. [CrossRef]

41. Chaudhry, A.; Rafiq, A.; Raza, J.; Gillani, S.-U.-H.; Malik, A.; Farqaleet, S.; Sami, A.; Awais, S. Staph Aureus as the most common cause of osteoarticular infection in dost â€ "1 Mayo Hospital, Lahore". Ann. King Edw. Med. Univ. 2015, 21, 136. [CrossRef]

42. Nylund, C.; Goudie, A.; Garza, J.; Fairbrother, G.; Cohen, M. Clostridium difficile infection in hospitalized children in the United States. Arch. Pediatr. Adolesc. Med. 2011, 165, 451-457. [CrossRef] 
43. Patel, S.J.; Oliveira, A.P.; Zhou, J.J.; Alba, L.; Furuya, E.Y.; Weisenberg, S.A.; Jia, H.; Clock, S.A.; Kubin, C.J.; Jenkins, S.G.; et al. Risk factors and outcomes of infections caused by extremely drug-resistant gram-negative bacilli in patients hospitalized in intensive care units. Am. J. Infect. Control 2014, 42, 626-631. [CrossRef]

44. de Blank, P.; Zaoutis, T.; Fisher, B.; Troxel, A.; Aplenc, K.J.R. Trends in Clostridium difficile infection and risk factors for hospital acquisition of Clostridium difficile among children with cancer. J. Pediatr. 2013, 163, 699-705.e1. [CrossRef]

45. Cabo Verde, S.; Almeida, S.; Matos, J.; Guerreiro, D.M.M.; Faria, T.; Botelho, D.; Santos, M.; Viegas, C. Microbiological assessment of indoor air quality at different hospital sites. Res. Microbiol. 2015, 166, 557-563. [CrossRef] [PubMed]

46. Sivagnanasundaram, P.; Amarasekara, R.; Madegedara, R.; Magana-Arachchi, E.A.D. Assessment of Airborne Bacterial and Fungal Communities in Selected Areas of Teaching Hospital, Kandy, Sri Lanka. Biomed. Res. Int. 2019, 2019, 7393926. [CrossRef] [PubMed]

47. Monteiro, A.; Almeida, B.; Paciência, I.; Cavaleiro Rufo, J.; Ribeiro, E.; Carolino, E.; Viegas, C.; Uva, A.; Cabo Verde, S. Bacterial Contamination in Health Care Centers: Differences between Urban and Rural Settings. Atmosphere 2021, 12, 450. [CrossRef]

48. Solomon, F.; Wadilo, F.; Arota, A.; Abraham, Y. Antibiotic resistant airborne bacteria and their multidrug resistance pattern at University teaching referral Hospital in South Ethiopia. Ann. Clin. Microbiol. Antimicrob. 2017, 16, 29. [CrossRef]

49. Allen, K.D.; Green, H. Hospital outbreak of multi-resistant Acinetobacter anitratus: An airborne mode of spread? J. Hosp. Infect. 1987, 9, 110-119. [CrossRef]

50. Dutkiewicz, J.; Mackiewicz, B.; Lemieszek, M.K.; Golec, M.; Milanowski, J. Pantoea agglomerans: A mysterious bacterium of evil and good. Part IV. Beneficial effects. Ann. Agric. Environ. Med. 2016, 23, 206-222. [CrossRef] [PubMed]

51. Dakić, I.; Morrison, D.; Vuković, D.; Savić, B.; Shittu, A.; Jezek, P.; Hauschild, T.; Stepanović, S. Isolation and molecular characterization of Staphylococcus sciuri in the hospital environment. J. Clin. Microbiol. 2005, 43, 2782-2785. [CrossRef] [PubMed]

52. Drozenová, J.; Petrás, P. Vlastnosti koaguláza-negativních stafylokoků izolovaných z hemokultur [Characteristics of coagulasenegative staphylococci isolated from hemocultures]. Epidemiol. Mikrobiol. Imunol. 2000, 49, 51-58. [PubMed]

53. Shittu, A.; Lin, J.; Morrison, D.; Kolawole, D. Isolation and molecular characterization of multiresistant Staphylococcus sciuri and Staphylococcus haemolyticus associated with skin and soft-tissue infec-tions. J. Med. Microbiol. 2004, 53, 51-55. [CrossRef]

54. Castellazzi, L.; Mantero, M.; Esposito, S. Update on the Management of Pediatric Acute Osteomyelitis and Septic Arthritis. Int. J. Mol. Sci. 2016, 17, 855. [CrossRef]

55. Taylor, T.A.; Unakal, C.G. Staphylococcus Aureus. [Updated 2021 Jul 21]. In StatPearls [Internet]; StatPearls Publishing: Treasure Island, FL, USA, 2021.

56. Hodgson, S.H.; Atkins, B.; Bejon, P.; Byren, I.; Whyllic, D.; Athanason, N.A.; Berendt, A.; McNally, M. The microbiology of chronic osteomyelitis: Prevalence of resistance to common empirical anti-microbial regimens. J. Infect. 2010, 60, 338-343. [CrossRef]

57. Inoue, S.; Moriyama, T.; Horinouchi, Y.; Tachibana, T.; Okada, F.; Maruo, K.; Yoshiya, S. Comparison of clinical features and outcomes of staphylococcus aureus vertebral osteomyelitis caused by methicillin-resistant and methicillin-sensitive strains. Springerplus 2013, 2, 283. [CrossRef] [PubMed]

58. Beronius, M.; Bergman, B.; Andersson, R. Vertebral osteomyelitis in Göteborg, Sweden: A retrospective study of patients during 1990-1995. Scand. J. Infect. Dis. 2001, 33, 527-532. [CrossRef]

59. Corrah, T.W.; Enoch, D.A.; Aliyu, S.H.; Lever, A.M. Bacteraemia and subsequent vertebral osteomyelitis: A retrospective review of 125 patients. QJM 2011, 104, 201-207. [CrossRef] [PubMed]

60. Clerc, O.; Prod'hom, G.; Greub, G.; Zanetti, G.; Senn, L. Adult native septic arthritis: A review of 10 years of experience and lessons for empirical antibiotic therapy. J. Antimicrob. Chemother. 2011, 66, 1168-1173. [CrossRef] [PubMed]

61. Stoesser, N.; Pocock, J.; Moore, C.E.; Soeng, S.; Hor, P.; Sar, P.; Limmathurotsakul, D.; Day, N.; Kumar, V.; Khan, S.; et al. The epidemiology of pediatric bone and joint infections in Cambodia, 2007-2011. J. Trop. Pediatr. 2013, 59, 36-42. [CrossRef] [PubMed]

62. Howard-Jones, A.R.; Isaacs, D.; Gibbons, P.J. Twelve-month outcome following septic arthritis in children. J. Pediatr. Orthop. B 2013, 22, 486-490. [CrossRef]

63. Khan, F.Y.; Abu-Khattab, M.; Baagar, K.; Mohamed, S.F.; Elgendy, I.; Anand, D.; Malallah, H.; Sanjay, D. Characteristics of patients with definite septic arthritis at Hamad General Hospital, Qatar: A hospital-based study from 2006 to 2011. Clin. Rheumatol. 2013, 32, 969-973. [CrossRef]

64. Peel, T.N.; Cheng, A.C.; Choong, P.F.; Buising, K.L. Early onset prosthetic hip and knee joint infection: Treatment and outcomes in Victoria, Australia. J. Hosp. Infect. 2012, 82, 248-253. [CrossRef] [PubMed]

65. Westberg, M.; Grøgaard, B.; Snorrason, F. Early prosthetic joint infections treated with debridement and implant retention: 38 primary hip arthroplasties prospectively recorded and followed for median 4 years. Acta Orthop. 2012, 83, 227-232. [CrossRef]

66. Bejon, P.; Berendt, A.; Atkins, B.; Green, N.; Parry, H.; Masters, S.; McLardy-Smith, P.; Gundle, R.; Byren, I. Two-stage revision for prosthetic joint infection: Predictors of outcome and the role of reimplantation microbiology. J. Antimicrob. Chemother. 2010, 65, 569-575; Erratum in J. Antimicrob. Chemother. 2011, 66, 1204.. [CrossRef]

67. Byren, I.; Bejon, P.; Atkins, B.L.; Angus, B.; Masters, S.; McLardy-Smith, P.; Gundle, R.; Berendt, A. One hundred and twelve infected arthroplasties treated with 'DAIR' (debridement, antibiotics and implant retention): Antibiotic duration and outcome. J. Antimicrob. Chemother. 2009, 63, 1264-1271, Erratum in: J. Antimicrob. Chemother. 2011, 66, 1203; Erratum in: J. Antimicrob. Chemother. 2013, 68, 2964-2965. [CrossRef]

68. Wertheim, H.F.; Melles, D.C.; Vos, M.C.; van Leeuwen, W.; van Belkum, A.; Verbrugh, H.A.; Nouwen, J.L. The role of nasal carriage in Staphylococcus aureus infections. Lancet Infect. Dis. 2005, 5, 751-762. [CrossRef] 
69. Mathieu, L.; Mottier, F.; Bertani, A.; Danis, J.; Rongiéras, F.; Chauvin, F. Management of neglected open extremity fractures in low-resource settings: Experience of the French Army Medical Service in Chad. Orthop. Traumatol. Surg. Res. 2014, 100, 815-820. [CrossRef]

70. Eidelman, M.; Bialik, V.; Miller, Y.; Kassis, I. Plantar puncture wounds in children: Analysis of 80 hospitalized patients and late sequelae. Isr. Med. Assoc. J. 2003, 5, 268-271. [PubMed]

71. Laughlin, R.T.; Reeve, F.; Wright, D.G.; Mader, J.T.; Calhoun, J.H. Calcaneal osteomyelitis caused by nail puncture wounds. Foot Ankle Int. 1997, 18, 575-577. [CrossRef] [PubMed]

72. Imoisili, M.A.; Bonwit, A.M.; Bulas, D.I. Toothpick puncture injuries of the foot in children. J. Pediatr. Infect. Dis. 2004, $23,80-82$. [CrossRef] [PubMed]

73. Thomas, S.; Palmer, R.; Chipungu, P.E.G. Reducing bacterial con-tamination in an Orthopedic Theatre ventilated by natural ventilation in a Developing Country. J. Infect. Dev. Ctries. 2016, 10, 518-522. [CrossRef] [PubMed]

74. Bielawska-Drózd, A.; Cieślik, P.; Bohacz, J.; Korniłłowicz-Kowalska, T.; Żakowska, D.; Bartoszcze, M.; Kocik, J. Microbiological analysis of bioaerosols collected from Hospital Emergency Depart-ments and ambulances. Ann. Agric. Environ. Med. 2018, 25, 274-279. [CrossRef] [PubMed]

75. Azimi, F.; Nabizadeh, R.; Alimohammadi, M.; Naddafi, K. Bacterial Bioaerosols in the Operating Rooms: A Case Study in Tehran Shariati Hospital. J. Air Pollut. Health 2016, 1, 215-218.

76. Mentese, S.; Rad, A.Y.; Arısoy, M.; Güllü, G. Seasonal and Spatial Variations of Bioaerosols in Indoor Urban Environments, Ankara, Turkey. Indoor Built Environ. 2012, 21, 797-810. [CrossRef]

77. Polednik, B. Aerosol and bioaerosol particles in a dental office. Environ. Res. 2014, 134, 405-409. [CrossRef] [PubMed]

78. Rendon, R.; Garcia, B.C.; Vital, P.G. Assessment of airborne bacteria in selected occupational environments in Quezon City, Philippines. Arch. Environ. Occup. Health 2017, 72, 178-183. [CrossRef]

79. Bartlett, J.G. Antibiotic-associated pseudomembranous colitis. Rev. Infect. Dis. 1979, 1, 530-539. [CrossRef] [PubMed]

80. Miller, B.A.; Chen, L.F.; Sexton, D.J.; Anderson, D.J. Comparison of the burdens of hospital-onset, healthcare facility-associated Clostridium difficile Infection and of healthcare-associated infection due to methicillin-resistant Staphylococcus aureus in community hospitals. Infect. Control Hosp. Epidemiol. 2011, 32, 387-390. [CrossRef]

81. Smits, W.K.; Lyras, D.; Lacy, D.B.; Wilcox, M.H.; Kuijper, E.J. Clostridium difficile infection. Nat. Rev. 2016, 2, 16020. [CrossRef] [PubMed]

82. Crobach, M.J.T.; Vernon, J.J.; Loo, V.G.; Kong, L.Y.; Péchiné, S.; Wilcox, M.H.; Kuijper, E.J. Understanding Clostridium difficile Colonization. Clin. Microbiol. Rev. 2018, 31, e00021-17. [CrossRef] [PubMed]

83. Eyre, D.W.; Griffiths, D.; Vaughan, A.; Golubchik, T.; Acharya, M.; O'Connor, L.; Crook, D.W.; Walker, A.S.; Peto, T.E. Asymptomatic Clostridium difficile colonisation and onward transmission. PLoS ONE 2013, 8, e78445. [CrossRef]

84. Kong, L.Y.; Eyre, D.W.; Corbeil, J.; Raymond, F.; Walker, A.S.; Wilcox, M.H.; Crook, D.W.; Michaud, S.; Toye, B.; Frost, E.; et al. Clostridium difficile: Investigating Transmission Patterns Between Infected and Colonized Patients Using Whole Genome Sequencing. Clin. Infect. Dis. Off. Publ. Infect. Dis. Soc. Am. 2019, 68, 204-209. [CrossRef]

85. Zacharioudakis, I.M.; Zervou, F.N.; Pliakos, E.E.; Ziakas, P.D.; Mylonakis, E. Colonization with toxinogenic C. difficile upon hospital admission, and risk of infection: A systematic review and meta-analysis. Am. J. Gastroenterol. 2015, 110, 381-390. [CrossRef]

86. Leffler, D.A.; Lamont, J.T. Clostridium difficile infection. N. Engl. J. Med. 2015, 372, 1539-1548. [CrossRef] [PubMed]

87. Angtuaco, T.; Sharma, V.; Corder, F.; Raufman, J.; Howden, C. Seroprevalence of H. pylori infection and symptoms of up-per gastrointestinal tract disease in two groups of healthcare workers. Dig. Dis. Sci. 2002, 47, 292-297. [CrossRef]

88. Napoli, C.; Marcotrigiano, V.; Montagna, M. Air sampling procedures to evaluate microbial contamination: A comparison between active and passive methods in operating theatres. BMC Public Health 2012, 12, 594. [CrossRef]

89. Nasser, A.; Zhang, X.; Yang, L.; Sawafta, F.; Salah, B. Assessment of Surgical Site Infections from Signs \& Symptoms of the Wound and Associated Factors in Public Hospitals of Hodeidah City, Yemen. Int. J. Appl. Sci. 2013, 3, 101-110.

90. Ensayef, S.; Al Shalchi, S.; Sabbar, M. Microbial contamination in the operating theatre: A study in a hospital in Baghdad. East. Mediterr. Health J. 2009, 15, 219-223. [CrossRef] [PubMed]

91. Bellido, F.; Hancock, R. Susceptibility and Resistance of P. aeruginosa to Antimicrobial Agents em in Pseudomona aeruginosa as an Opportunistic Pathogen; Campa, M., Bendinelli, M.F.H., Eds.; Springer: Boston, MA, USA, 1993; pp. 321-348.

92. Peña, C.; Dominguez, M.A.; Pujol, M.; Vardarguer, R.; Gudiol, F.; Ariza, J. An outbreak of carbapenem-resistant Pseudomonas aeruginosa in a urology ward. Clin. Microbiol. Infect. 2003, 9, 938-943. [CrossRef] [PubMed]

93. Peleg, A.; Seifert, H.; Paterson, D. Acinetobacter baumannii: Emergence of a successful pathogen. Clin. Microbiol. Rev. 2008, 21, 538-582. [CrossRef] [PubMed]

94. Paterson, D. Resistance in gram-negative bacteria: Enterobacteriaceae. Am. J. Med. 2006, 119, S20-S70. [CrossRef] 